\title{
Do Postmenopausal Women have Thinner Central Corneal Thickness as Compared to Women in Reproductive Age Group?
}

\author{
Dr. Rashmi S. ${ }^{1}$, Dr. Soni Soman ${ }^{2}$, Dr. Anupama B. ${ }^{3}$, Dr. Vidya Hegde ${ }^{4}$, \\ Dr. Rashmi Jain ${ }^{5}$, Dr. Akshaya K. M. ${ }^{6}$
}

\begin{abstract}
Purpose: Certain changes occur in corneal tissue in women after menopause due to hormonal effects. Purpose of this study is to find out whether postmenopausal women have thinner central corneal thickness (CCT) when compared women of reproductive age group. Measurement of CCT is important for the success of refractive surgeries and for the calculation of intra ocular pressure. Methods: Central corneal thickness was measured in 60 eyes of 30 healthy postmenopausal women using ultrasound pachymetry. Thirty women in reproductive age group were taken as control group. Statistical analysis was performed using paired test. Result: Postmenopausal women have significantly thinner CCT as compared to women in reproductive age group (534.50 +/- 12.13 microns, $558.18+/-9.15$ microns respectively, $p<0.001)$. Conclusion: CCT is significantly reduced in postmenopausal women. This revelation warrants the need of accurate and periodic CCT measurements in every woman especially after refractive surgery.
\end{abstract}

Keywords: Central corneal thickness, post menopausal women, reproductive age group, hormones, cornea

\section{Introduction}

Even though menopause is a physiological condition, certain changes occur in the corneal tissue due to hormonal effects. The current study intended to study any change in central corneal thickness (CCT) among women after menopause. Changes in CCT can affect the success of corneal refractive surgery. Also false readings in IOP measurements affect the diagnosis and monitoring of glaucoma. Therefore it is necessary to recalculate applanation values based on corneal thickness in every patient, especially after refractive surgery.

\section{Method}

Institutional ethics committee clearance was obtained and structured Performa was made. We recruited 30 healthy postmenopausal women for the study (Group1) and 30 healthy women in reproductive age group as control group (Group 2) by convenience sampling. Informed written consent was taken from all the participants.

CCT was measured in all women in both eyes using ultrasound pachymetry.

Statistical analysis was performed using SPSS statistical software (version 17) . The data were entered in Microsoft excel sheet and was analyzed using paired test. A $p$ value of $<0.05$ was considered as significant.

Group 1:

60 eyes of 30 postmenopausal women

\section{Inclusion Criteria}

Women who have attained menopause (i.e ,women who did not menstruate for the last 12 consecutive months).We included women in age group between 50-65 years only.

\section{Exclusion Criteria:}

1) Women less than 50 years (because even after a women stops menstruating the for past 12 months, we cannot group her as postmenopausal or perimenopausal unless hormone level estimation of oestrogen and FSH to assure that the patient has attained her menopause)

2) Women more than 65years (to avoid effect of old age on CCT, if any)

3) Women with eye disease or using eye drops

4) Women with dry eye (dry eye causes decrease in CCT)

5) Women on HRT (hormonal influence on CCT)

6) Women with hypertension, diabetes, thyroid disease, mental illness, and on medications for the same

\section{Group 2:}

60 eyes of 30 healthy women (control group) in reproductive age group ranging from 25-40years of age

\section{Exclusion:}

1) Pregnancy

2) Recent history of childbirth/ abortion

3) Lactating women

4) Women on oral contraceptive pills

5) Women with irregular periods or polycystic ovarian disease

6) Women with any systemic diseases/on medications

7) Women with premature menopause

\section{Results}

The mean central corneal thickness values in both groups were found and compared. With paired t test results there was a statistically significant difference in the mean CCT between reproductive age group and postmenopausal age group , p value $<0.001$. Postmenopausal women have significantly thinner CCT as compared to women in reproductive age group (534.50 +/- 12.13 microns, 558.18 $+/-9.15$ microns respectively, $\mathrm{p}<0.001)$. 


\section{International Journal of Science and Research (IJSR) \\ ISSN (Online): 2319-7064 \\ Index Copernicus Value (2013): 6.14 | Impact Factor (2014): 5.611}

Table 1: Comparison of CCT range among the different groups

\begin{tabular}{|c|c|c|}
\hline $\begin{array}{c}\text { CCT range } \\
\text { (microns) }\end{array}$ & $\begin{array}{c}\text { Women in reproductive } \\
\text { age group }\end{array}$ & $\begin{array}{c}\text { Postmenopausal } \\
\text { women }\end{array}$ \\
\hline $510-519$ & - & 10 \\
\hline $520-529$ & - & 11 \\
\hline $530-539$ & - & 20 \\
\hline $540-549$ & 14 & 8 \\
\hline $550-559$ & 22 & 11 \\
\hline $560-569$ & 16 & - \\
\hline $570-579$ & 8 & - \\
\hline
\end{tabular}

Table 2: Mean CCT among the different groups

\begin{tabular}{|c|c|}
\hline & Mean CCT \\
\hline Group1 & 558.18 \\
\hline Group 2 & 534.50 \\
\hline
\end{tabular}

Table 3: Mean CCT and standard deviation

\begin{tabular}{|l|c|c|c|c|}
\hline Groups & $\begin{array}{c}\text { Number of } \\
\text { participants }\end{array}$ & $\begin{array}{c}\text { Mean } \\
\text { CCT }\end{array}$ & $\begin{array}{c}\text { Standard } \\
\text { Deviation }\end{array}$ & p value \\
\hline Group1 & 60 & 558.18 & 9.15 & \multirow{2}{*}{$12.71(<\mathbf{0 . 0 0 1 )}$} \\
\hline Group 2 & 60 & 534.50 & 12.13 & \\
\hline
\end{tabular}

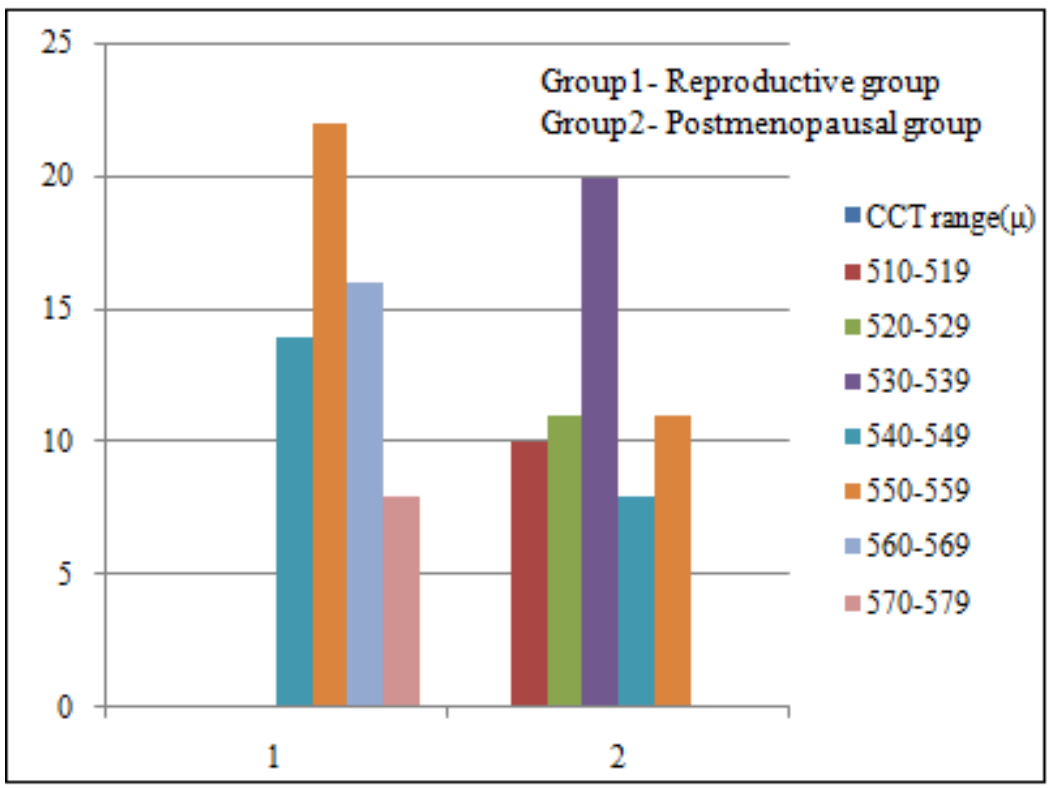

Figure 1: Showing Comparison of CCT range among the different groups

\section{Discussion}

Central corneal thickness (CCT) is an important indicator of corneal health status. It is an essential tool in assessment and management of corneal diseases as it gives an estimate of the corneal barrier and endothelial pump function. Also, CCT is a measure of corneal rigidity and consequently has an impact on the accuracy of IOP measurement by applanation tonometry. Thicker cornea when subjected to applanation, result in falsely high IOP reading. Conversely, thinner corneas give falsely low readings. The correction value is $1 \mathrm{~mm} \mathrm{Hg}$ per 25 micron change in corneal thickness. Hence we need to recalculate IOP values after applying CCT correction values.

With the advent of laser refractive surgery and its increased popularity there has been a heightened interest in CCT. Measuring the CCT is essential to determine a patient's eligibility for laser refractive surgery. Also CCT has a prognostic significance for the determination of success of surgery and in preventing possible post-surgical complications. Patients with relatively thin CCT can have post surgical complications like keratectasia. Also there is change in applanation IOP measurements in refractive surgery patients due to reduction in CCT (after ablation of corneal stroma). CCT corrected IOP is essential for accurate diagnoses of glaucoma and ocular hypertension. It is important that we do not under -diagnose glaucoma in patients who have undergone corneal refractive surgery.
It has CCT in general population is related to many demographic and ocular factors studies have shown that gender, race/ethinicty and age may influence CCT ${ }^{(1)}$

Age related differences in CCT have been noted in some ethnic groups, particularly later in life. S Hahn studied CCT in latino population and found CCT is thinner in elderly latinos aged more than 70 years. ${ }^{(1)}$ But, according to study by A.Siu, ageing has no significant effect on human corneal thickness. ${ }^{(2)}$

Most studies have shown no gender related differences ${ }^{(1)}$. However, there are certain hormone induced changes in corneas of healthy women.

Gonadal hormones take part in the homeostasis and functions of the cornea which are mediated via hormone receptors present in corneal epithelial, stromal and endothelial cells ${ }^{(3)}$. The combined effect of estrogen and progesterone can be seen on a women's cornea during all reproductive phases like puberty, pregnancy, lactation, and menopause and even due to effect of any abortions, oral contraceptive pills or hormone replacement therapy.

Changes in corneal curvature, thickness and sensitivity during the woman's menstrual cycle have been detected and attributed to endocrinal influences ${ }^{(4,5)}$.

Ghahfarokhi NA et al evaluated CCT alterations durning menstrual cycle. They concluded that the thickest cornea 


\section{International Journal of Science and Research (IJSR) \\ ISSN (Online): 2319-7064 \\ Index Copernicus Value (2013): 6.14 | Impact Factor (2014): 5.611}

durning menstrual cycle is achieved at the ovulation time and the thinnest at the end of the end of cycle and this should be taken into account whilst plan to do a corneal refractive surgery ${ }^{(6)}$.

During pregnancy, changes in the corneal thickness, curvature, sensitivity have been found. Changes in the refraction and contact lens intolerance can occur (7). Refractive surgeries are contraindicated.

After menopause the serum levels of follicle stimulating hormone increases and the level of estrogen declines. There are certain changes in women's cornea including changes in CCT and corneal curvature after menopause.

Aydin E et al have investigated a negative, but significant, correlation between estrogen level and horizontal corneal curvatures in postmenopausal women. So, they speculated that a decrease in the estrogen level of women in the postmenopausal term may cause a steeping of corneal horizontal curvature. They suggest that refractive surgeons should keep these points in mind and consider precautionary measures in patients during their menstrual cycle or entering menopause ${ }^{(8)}$.

The main action of estrogen is to enhance sodium reabsorption by the tissues leading to water retension ${ }^{(6)}$. However apart from this, one more action of estrogen is that it modulates biomechanical properties of cornea. Not only does an elevated estrogen level results in biomechanical changes, but also a reduced level ${ }^{(9)}$. So any variation in the level of estrogen can result in decrease in strength of cornea making it susceptible for bulging. Changes corneal tissue due to fluctuations of estrogen level is known during the menstrual cycle, pregnancy and use of oral contraceptives. Currently much interest is focused on research to find out influence of estrogen on corneal stability after corneal refractive surgeries as seen in studies concerning regression after Lasik. Also women have nine fold higher risks for developing keratectasia after LASIK than men. Estrogen has a stiffness-reducing effect on the cornea that does not play an important role under normal conditions but can be clearly seen in a biomechanically weakened cornea such as after LASIK. The stiffness changing effect of estrogen can be explained at a molecular level. The effect of hormones on the cornea (even more so in post LASIK corneas) leading to development of kerectasia should not be under estimated. ${ }^{(9)}$

It is suggested that there is decrease in CCT after menopause. Keskin N et al evaluated CCT difference between women in premenopausal and postmenopausal period ${ }^{(10)}$.They found CCT was significantly reduced in postmenopausal women compared to premenopausal women (521.18+/- 37.97 microns,561+/- 42.84 microns respectively ,p $<0.005$ ).They have also estimated the serum hormonal levels of the participants.

In our study we have compared the CCT values of postmenopausal women with that of women in reproductive age group. We found that postmenopausal women have significantly thinner CCT as compared to women in reproductive age group (534.50 +/- 12.13 microns, 558.18 $+/-9.15$ microns respectively, $\mathrm{p}<0.001)$.
Another study compared corneal thickness values of postmenopausal women with dry eye and without dry eye. They concluded that dry eye status further lowers the corneal thickness in postmenopausal women ${ }^{(11)}$.

More studies are needed to assess the relevance corneal changes after menopause and its impact on detection and monitoring of corneal problems or glaucoma.

Two limitations of our study need to be mentioned. One is that we have considered that women are postmenopausal based on their history only. We have not done any hormonal evaluation like serum analysis of estrogen and follicle stimulating hormones. The study would have carried more weight age if we had done and then correlated the CCT values with this.

Second limitation is that in the control group (women in reproductive age group) we have not found out in which day of menstrual cycle they are in, on the day when we measured CCT.

\section{Conclusion}

The possibilities of regression and risk of keratectasia due to hormonal effects in women (structure-modulating effect of fluctuating levels of estrogen on corneal tissue) should be kept in mind during patient selection and follow up visits after corneal refractive surgeries.

Secondly, changes in CCT need to considered in every women (and more so if they have undergone a corneal refractive surgeries) so that we do not miss a case of glaucoma. It is essential to recalculate the applanation intra ocular pressure values according to CCT periodically. This helps in monitoring of glaucoma patients with precision.

\section{References}

[1] Hahn S, Azen S, Ying-Lai M et al. Central corneal thickness in Latinos. Invest Ophthalmol Vis Sci 2003;44: 1508-12.

[2] Siu A, Herse P. The effect of age on human corneal thickness: statistical implications of power analysis. Acta Ophthalmol 1993; 71: 51-6.

[3] Gupta P D, Kaid Johar et al. Sex hormone receptors in the human eye. Survey of ophthalmology 2005;50: 27484.

[4] Giuffre, Giuseppe et al. Variations in central corneal thickness during the menstrual cycle in women. Cornea 2007;26:144-6.

[5] Kiely, Patricia M, Leo G et al. Menstrual cycle variations of corneal topography and thickness. Am J Optom Physiol Opt 1983;60: 822-9.

[6] NA Ghahfarokhi , Vaseghi A, Ghoreishi M, Peyman A, Dehghani A. Evaluation of corneal thickness alterations during menstrual cycle in productive age women. Indian J Ophthalmol 2015;63:30-2.

[7] Samra KA. The eye and visual system in pregnancy, what to expect? An in-depth review. Oman J Ophthalmol 2013;6:87-91.

[8] Aydin E, Demir HD, Demirturk F, Caliskan AC, Aytan $\mathrm{H}$, Erkorkmaz U . Corneal topographic changes in

\section{Volume 5 Issue 3, March 2016}




\section{International Journal of Science and Research (IJSR) \\ ISSN (Online): 2319-7064}

Index Copernicus Value (2013): 6.14 | Impact Factor (2014): 5.611

premenopausal and postmenopausal women. BMC Ophthalmol 2007; 7: 9 .

[9] Spoerl E, Zubaty V, Raiskup Wolf F, Pillunat LE. Oestrogen-induced changes in biomechanics in the cornea as a possible reason for keratectasia. $\mathrm{Br} J$ Ophthalmol 2007; 91:1547-50.

[10]Keskin N, Cantürk S, Aydin S, Saygili H, Ozgün C. An objective method to determine corneal changes during menopause. Clin Exp Obstet Gynecol. 2009;36:176-8

[11] Sanchis-Gimeno, Juan A et al. Reduced corneal thickness values in postmenopausal women with dry eye. Cornea 2005;24: 39-44. 